\title{
Posterior Urethral Valve in Twins - A Case Report
}

Authors

\section{Dr Muhammed Shareef Thenath ${ }^{1}$, Dr Iainehskhem Lyngdoh Mawphlang ${ }^{2}$, Prof Kh. Ibochouba Singh ${ }^{3}$, Dr Sunilbala $K^{4}$, Dr Kumar Shantnu ${ }^{1}$, Dr Nini Kadu², Dr Anto Ferdine Vaik. $\mathbf{P}^{1}$}

${ }^{1}$ Post Graduate Trainee $3^{\text {rd }}$ Year, Department of Pediatrics, Regional Institute of Medical Sciences, Imphal

${ }^{2}$ Post Graduate Trainee $2{ }^{\text {nd }}$ Year, Department of Pediatrics, Regional Institute of Medical Sciences, Imphal

${ }^{3}$ Professor, Department of Pediatrics, Regional Institute of Medical Sciences, Imphal

${ }^{4}$ Assistant Professor, Department of Pediatrics, Regional Institute of Medical Sciences, Imphal

Abstract
Posterior Urethral Valves occur 1 in 5000 live births. 1 The spectrum of renal dysfunction and subsequent
functional outcomes vary widely in children. We report a case of a one-day-old second male twin who was
delivered at 31 weeks of gestation and presented with respiratory distress. Ultrasound and VCUG was done,
and the diagnosis of posterior urethral valve was made.

\section{Introduction}

Posterior urethral valves (PUV) are the most common congenital cause of bladder outflow obstruction in male neonates. ${ }^{2}$ Posterior urethral valves are obstructing flaps of tissue in the male urethra that prevent normal urine flow from the bladder. They result from the formation of a thick, valve-like membrane from tissue of Wolffian duct origin (failure of regression of the mesonephric duct) that courses obliquely from the veromontanum to the most distal portion of the prostatic urethra. This is thought to occur in early gestation (5-7 weeks). Most PUVs are diagnosed after detection of hydronephrosis by routine prenatal ultrasound. Typical prenatal findings include bilateral hydrouretero-nephrosis, distended bladder and a dilated prostatic urethra. Posterior urethral valves (PUV) in discordant twins are seldom reported. We reported this case for this reason.

\section{Case Report}

A 1-day-old second male twin of 31 weeks gestation presented to us with complaints of respiratory distress. The patient was the second twin who was delivered by vertex presentation following breech delivery of the first twin. Both the twins were admitted in the NICU for very low birth weight and respiratory distress. Prior Ultrasound reports in the $3^{\text {rd }}$ semester showed hydronephrosis in the $2^{\text {nd }}$ twin. Few days after admission, the $2^{\text {nd }}$ twin had poor passage of urine. Abdominal examination revealed a distended bladder with mild abdominal distension. Other systemic examinations were within normal limits.

Routine blood examinations were done including sepsis screening and total serum bilirubin. The patient's blood group was A positive. Sepsis screening was negative while total serum bilirubin 
was $5.1 \mathrm{mg} / \mathrm{dl}$. Other hematological parameters were within normal limits.

Ultrasound was done (Figure 1) which shows persistent dilatation of the urinary bladder with a thickened bladder wall $(>2 \mathrm{~mm})$. The proximal urethra was dilated resembling a keyhole appearance suggestive of posterior urethral valve. Urologist was informed and as per advises; Voiding cystourethrography (VCUG) was done. VCUG shows dilatation of the prostatic urethra confirming the diagnosis of posterior urethral valve.

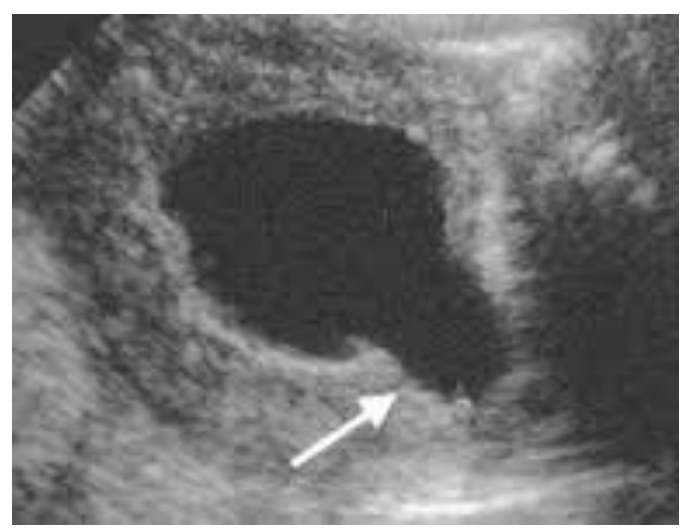

Figure 1: Ultrasound showing keyhole appearance

\section{Discussion}

Morgagni was the first to describe PUV in 1717. ${ }^{3}$ However the most frequently referenced, earliest description of PUV is credited to Langenbeck in 1802, who commented on valve-like folds in autopsy specimens. Langenbeck did not infer any clinical significance to these findings. ${ }^{1}$ In 1832 Velpeau described several anatomical specimens in which there were posterior urethral valve-like folds that might be of clinical importance. Tolmatschew in 1870 was the first to recognize this as a pathological entity and propose a theory about its embryology. ${ }^{4}$ Finally, Young et al described PUV as a clinical and pathological condition in 12 patients while giving an accurate description of the clinical presentation and the anatomy of valves in 1919. ${ }^{5}$

The exact etiology of PUV is unknown, but it appears to be a multifactor gene mediated embryopathy. ${ }^{6}$ During embryogenesis, the most caudal end of the Wolffian duct is absorbed into the primitive cloaca at the site of the future verumontanum in the posterior urethra. In healthy males, the remnants of this process are the posterior urethral folds, called plicaecolliculi. Histological studies suggest that PUV is formed at approximately 4 weeks' gestation, as the Wolffian duct fuses with the developing cloaca. When the insertion of the mesonephric ducts into the cloaca is anomalous or too anterior, normal migration of the ducts is impeded, and the ducts fuse anteriorly resulting in the formation of abnormal ridges or folds, which are believed to be the origins of PUV. ${ }^{7}$

Young in 1919 described three different types of valves based on the orientation of the valves and their relationship to the verumontanum:

Type I: Two membranous structures in the posterior urethra originating from the caudal end of the verumontanum rising along the lateral margin of the urethra on each side meeting at 12 o'clock.

Type II: Membranes arising from verumontanum and attached cranially to the bladder neck.

Type III: Circular diaphragm in the region of the caudal end of the verumontanum with a central defect.

They further subdivided the classification of types I and III into a and b. Type III lesions were thought to consist of a membrane with a hole above (type IIIa) or below (type IIIb) the verumontanum, but without attachment to the verumontanum. ${ }^{8}$

Neonates with PUV who are not diagnosed before births may present with delayed voiding or poor urinary stream, abdominal mass, failure to thrive, poor feeding, lethargy, urosepsis or urinary ascites. In addition, respiratory distress at birth due to pulmonary hypoplasia may be the initial sign of urethral obstruction. ${ }^{9}$ In infants, poor urinary stream and recurrent urinary tract infection are common. Older boys may present with recurrent UTI, diurnal enuresis in boys older than 5 years, secondary diurnal enuresis, voiding pain or dysfunction, and decreased force of urinary stream.

Examination findings in the newborn include poor breathing movements, small chest cavity, palpable walnut-sized bladder (hypertrophy detrusor muscle), abdominal distension (ascites), potter facies and limb deformities (skin dimpling) and indentation of 
the knees and elbows due to compression within the uterus.

Diagnosis is ascertained by a combination of antenatal evaluation, which includes maternal ultrasound and fetal urinary biochemical assessment for renal function, and postnatal evaluation, which consists of renal and bladder ultrasonography, voiding cystourethrography, renal scintigraphy and urodynamic studies. Ultrasonography shows dilated bladder along with dilatation of prostatic urethra resembling keyhole appearance. ${ }^{10}$ VCUG confirms the diagnosis.

\section{References}

1. Krishnan A, de Souza A, Konijeti R, Baskin LS. The anatomy and embryology of posterior urethral valves. J Urol 2006; 175:1214-1220.

2. Imaji R, Moon D, Dewan PA. Congenital posterior urethral obstruction. In: Prem P, eds. Newborn Surgery, 2nd ed. London: Arnord, 2003: 856-866.

3. Morgagni JB. Seats and Causes of Diseases investigated by Anatomy. In: Millar A, Cadell T, eds. Five books, containing a Great Variety of Dissections with Remarks to which are added very accurate and copious indexes of the principal things and Names Therein contained. London: Johnson and payne, 1769:540-556.

4. Tolmatschew N. A case of Semilunaren flaps of the urethra and vergrossertervesicula prostatice. Archiv Path Anat 1870;11:348.

5. Young HH, Frontz WA, Baldwin JC. Congenital obstruction of the posterior urethra. J Urol, 3: 289-365, 1919. J Urol 2002; 167:265-268.

6. Borzi PA, Beasley SW, Fowler R. Posterior urethral valves in non twin siblings. $\mathrm{Br} \mathrm{J}$ Urol 1992;70:201.

7. Elder JS, Shapio E. Posterior urethral valves. In: Ashcraft KW, Holcomb GW, Murphy JP, eds. Pediatric Surgery, 4th ed. Philadelphia: Elsevier Saunders, 2005: 781-792.
8. Dewan PA, Zappala SM, Ransley PG, Duffy PG. Endoscopic reappraisal of the morphology of congenital obstruction of the posterior urethra. Br J Urol 1992;70:439-444.

9. Sudarsanan B, Nasir AA, Puzhankara R, Kedari PM, Unnithan GR, Damisetti KR. Posterior urethral valves: a single center experience over 7 years. PediatrSurgInt 2009;25:283-287.

10. Cohen HL, Zinn HL, Patel A, Zinn DL, Haller JO. Prenatal sonographic diagnosis of posterior urethral valves: identification of valves and thickening of the posterior wall. J ClinUltrasound 1998;26:366-37 